\title{
WOLLASTONITA EM ASSOCIAÇÕES CÁLCICAS DE FÁCIES GRANULITO, CACONDE, SP*
}

\author{
MARCOS AURÉLIO FARIAS DE OLIVEIRA** e \\ FRANCISCO RUBENS ALVES**
}

\begin{abstract}
Wollastonite-rich rocks are found interlayered with banded calcsilicate granulites, in the Caconde region, São Paulo, Brazil.

The chief mineral components of the former rocks, besides wollastonite, are: diopside, calcic plagioclase (bytownite), garnet, calcic scapolite, calcite and quartz.

Although it is not a commonly cited mode of formation, field and petrographic data indicate that the wollastonite is a product of high grade regional metamorphism.
\end{abstract}

INTRODUÇÃo A presença de wollastonita em calcários impuros submetidos a metamorfismo regional é poucas vezes referida na literatura geológica.

Em seu trabalho de 1973, Miyashiro reúne alguns exemplos da ocorrência desse mineral em rochas formadas sob condições de metamorfismo regional; o exposto por esse Autor permite concluir que as ocorrências registradas dizem respeito a áreas em que o metamorfismo atuante foi de baixa pressão, como sejam as de Shiojiri (Katada, 1965) e da porção central do planalto de Abukuma (Miyashiro, 1953, 1958), ambas no Japão, e de Aracena na Espanha (Bard, 1969). Como exemplo do aparecimento de wollastonita em metamorfismo de pressão média é referido no trabalho de Misch (1964), em que é descrita uma seqüência de metassedimentos carbonáticos, intercalados a metapelitos contendo cianita e sillimanita, da região de Nanga Parbat, noroeste dos Himalaias. As associações calcossilicáticas dessa área são agrupadas em três zonas de metamorfismo progressivo:

1. Zona da calcita - quartzo - grossulária

2. Zona da wollastonita - grossulária - quartzo

3. Zona da wollastonita - anortita (bytownita)

Essas citações se referem a áreas em que o metamorfismo atingiu condições de PT da fácies anfibolito. Em regiões tipicamente granulíticas a presença de wollastonita é verificada através dos trabalhos de Hapuarachchi (1968) e Katz (1972), em que são descritos cordierita granulitos aos quais se associam rochas contendo wollastonita-diopsídio-escapolita-calcita-quartzo do sudoeste do Ceilão, e de Mukherjee et al. (1972), que estudaram associações semelhantes: diopsídio, wollastonita, escapolita, granada etc. intercalados em kondalitos e leptinitos da região leste de Ghats, Índia.

No presente trabalho, é feita a descrição da wollastonita que ocorre em rochas calcossilicáticas associadas a granulitos e migmatitos na região de Caconde, SP (Fig. 1).

*Trabalho realizado com auxílio do Conselho Nacional de Desenvolvimento Científico e Tecnológico (CNPq)

**Departamento de Mineralogia e Petrologia, Instituto de Geociências, Universidade de São Paulo, Caixa Postal 20899, São Paulo, SP, Brasil 


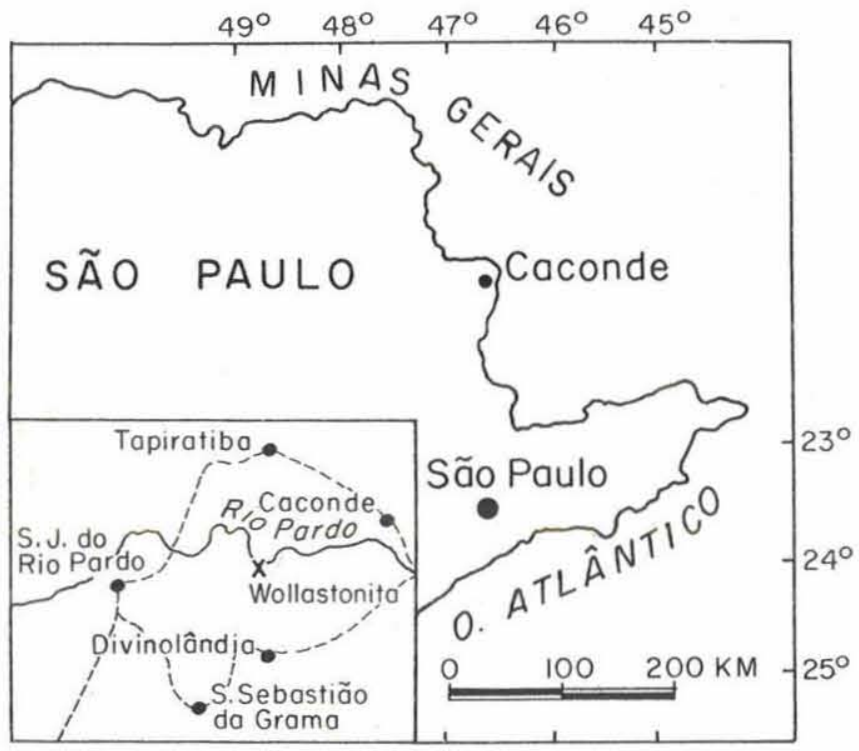

Figura 1

OCORRÊNCIA As rochas calcossilicáticas ocorrem em pequenas manchas ou níveis restritos, de certa continuidade lateral, em toda a região entre São José do Rio Pardo e Caconde (Oliveira, 1973; e Oliveira e Alves, no prelo).

Todas as ocorrências são petrográfica e mineralogicamente muito semelhantes e as mais próximas a São José do Rio Pardo foram estudadas por Oliveira e Hypolito (no prelo), fazendo os autores referência à presença subordinada de restos de wollastonita em uma amostra.

Além dos tipos calcossilicáticos, um grande corpo de mármore dolomítico, estudado por Gomes et al. (1966), foi registrado nas proximidades.

A ocorrência de que trata este trabalho se notabiliza pela presença de bandas de espessura decimétrica, maciças, quase puras, de wollastonita. $\mathrm{O}$ afloramento único se localiza a meia distância entre São José do Rio Pardo e Caconde, exatamente em frente à ponte de aço da Fazenda Fortaleza, na margem direita do Rio Pardo. Os níveis calcossilicáticos, representados pela letra W, na Fig. 2, se intercalam a migmatitos graníticos porfiroblásticos, migmatitos quartzíticos e hiperstênio granulitos (charnockitos), juntamente com leitos de quartzito e um leito de granada gnaisses com sillimanita (Oliveira e Alves, no prelo).

As rochas nesse local ora estão in situ, ora são blocos que se amontoam ao longo do barranco, não chegando a aparecer seqüências bem definidas, principalmente para leste, onde encontramos blocos ora de quartzitos ora de granulitos alaskíticos, ora de charnockitos. O leito do rio, em frente ao ponto onde se encontram as camadas com wollastonita, apresenta extensa exposição de charnockitos.

PETROGRAFIA As porções calcossilicáticas se apresentam bandadas e foliadas. O bandamento, aparentemente regular e retilíneo, se mostra bastante dobrado nas seções perpendiculares à direção da foliação no local $\left(60^{\circ} \mathrm{N}\right.$ a $70^{\circ} \mathrm{E}$, com suave mergulho para sul), sendo as dobras de dimensões reduzidas do tipo similar, assimétricas e bastante inclinadas. As bandas, de espessuras milimétricas a decimétricas, apresentam cores bastante variadas (brancas, cinzentas, esverdeadas etc.), emprestando aspecto fitado à rocha. Apa- 

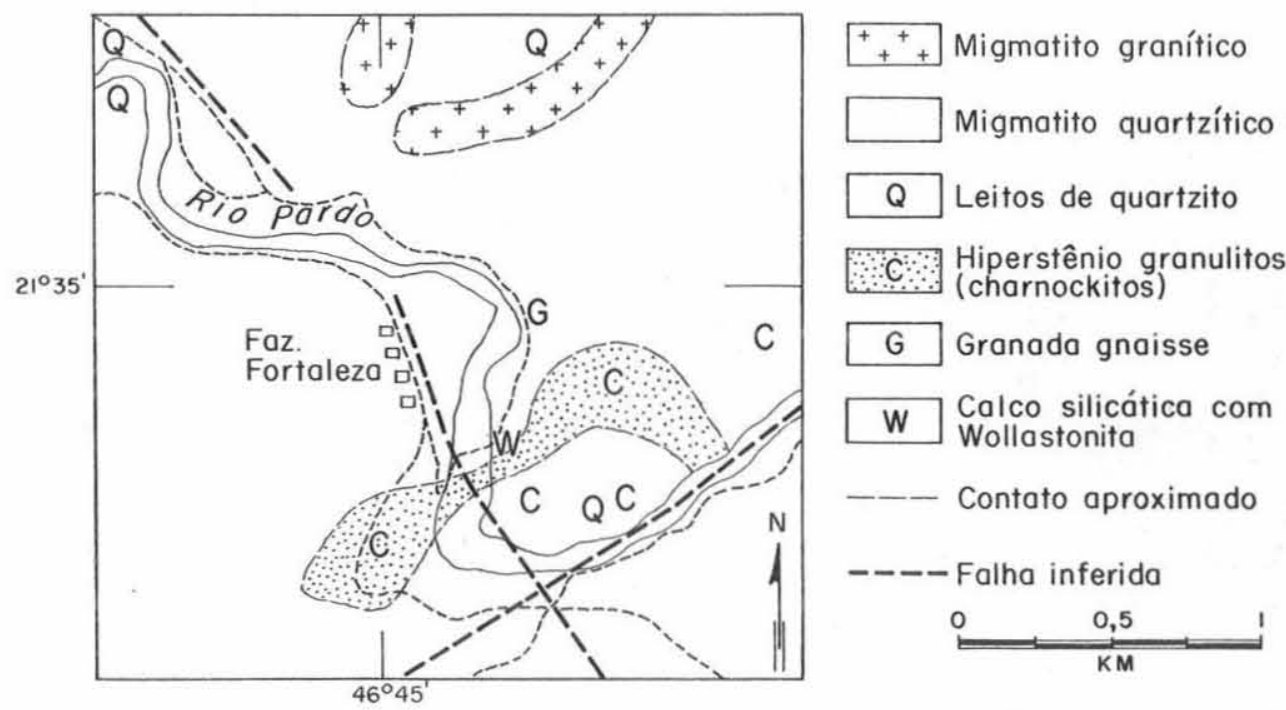

Figura 2

rentemente, em escala mesoscópica, a foliação se apresenta paralela ao bandamento. Em amostras manuais, algumas serradas, são notáveis a orientação planar (e possivelmente linear) da wollastonita, a obliqüidade entre o bandamento e a orientação dos grãos das porções quartzosas (observada somente à lupa binocular), e a presença constante de sulfetos disseminados.

O exame microscópico revela que o bandamento se deve a diferenças de composição mineralógica. São tipos, às vezes completamente distintos, que obedecem à alternância até submilimétrica, havendo casos de cinco tipos em uma mesma seção delgada. Em resumo, as bandas poderiam ser caracterizadas como se segue:

1. Quartzitos, com proporções variadas de diopsídio, wollastonita, escapolita, granada, plagioclásio (An 40/50), clinozoisita e calcita, e, acessoriamente, titanita, opacos e apatita.

2. Níveis quartzo-feldspáticos, onde predominam amplamente quartzo e plagioclásio (An 45/50), comparecendo diopsídio e esparsamente alguns minerais de alteração.

3. Níveis de quartzo e diopsídio, com comparecimento subordinado de wollastonita, escapolita, bytownita (An 70/90), granada, clinozoisita e calcita.

4. Níveis quase puros de diopsídio, com titanita e freqüentemente clinozoisita e calcita.

5. Níveis de wollastonita e diopsídio em proporções variadas, ocorrendo ainda microclínio, quartzo, clinozoisita, calcita e acessoriamente titanita, opacos e apatita.

6. Níveis feldspáticos (andesina), com diopsídio, quartzo, biotita, titanita, apatita e opacos.

7. Níveis ricos em escapolita, com diopsídio, microclínio, granada, andesina, clinozoisita, calcita e titanita.

De modo geral, as rochas apresentam granulação fina, submilimétrica, variando em torno de $0,5 \mathrm{~mm}$. Os minerais prismáticos, principalmente, atingem com frequêencia dimensões da ordem de 1 a $3 \mathrm{~mm}$. Além disso, observa-se forte tendência à isorientação de todos os minerais, inclusive do quartzo. Utilizando-se o esquema proposto por Moore (1970), acrescido do termo nematoblástico (significado usual, Williams et al., 1970), podemos dizer que as rochas apresentam texturas granoblásticas, seriadas e interlobadas 


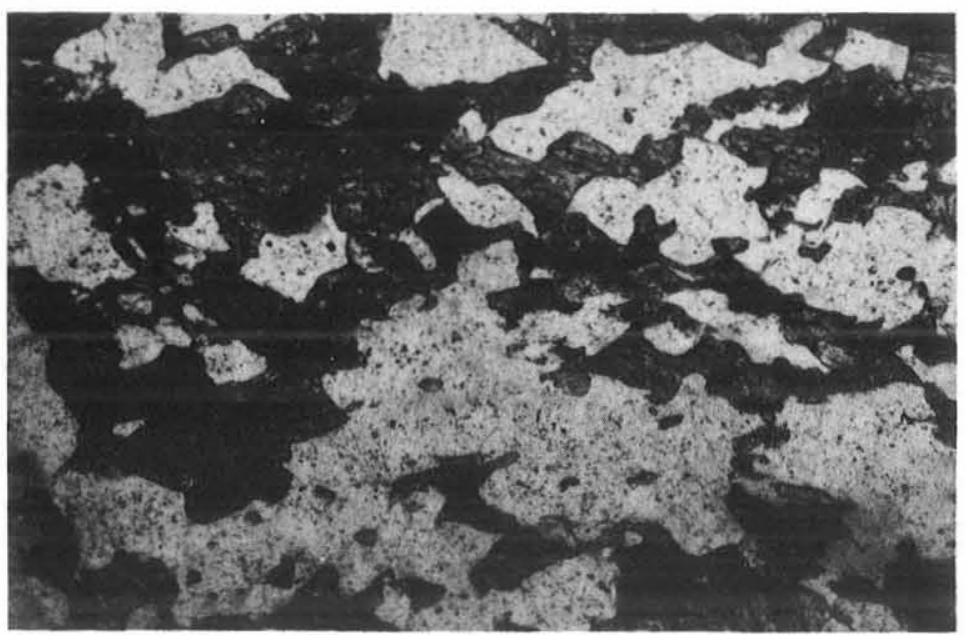

Fotomicrografia 1

Quartzo em formas convexas envolvendo diopsídio com formas reentrantes côncavas ou em pequenas gotas. As porções escuras são de clinozoisita. Observam-se duas tendências direcionais (uma NE e uma NW). Textura granoblástica interlobada a amebóide, seriada. Polarizadores descruzados. $\times 48$

(Fotomicrografia 1). Os níveis mais ricos em diopsídio e wollastonita se apresentam ou granoblásticos poligonais ou nematoblásticos (Fotomicrografia 2).

Nas amostras examinadas, foi possível distinguir as seguintes associações mineralógicas:

1. Diopsídio - Escapolita - Andesina ( \pm Microclínio, \pm Granada $)$

2. Diopsídio - Escapolita - Granada

3. Diopsídio - Escapolita - Bytownita

4. Diopsídio - Escapolita - Microclínio

5. Diopsídio - Escapolita - Calcita (?)

6. Diopsídio - Wollastonita - Bytownita

7. Diopsídio - Wollastonita - Microclínio

8. Diopsídio - Wollastonita - Granada

9. Diopsídio - Andesina - Biotita

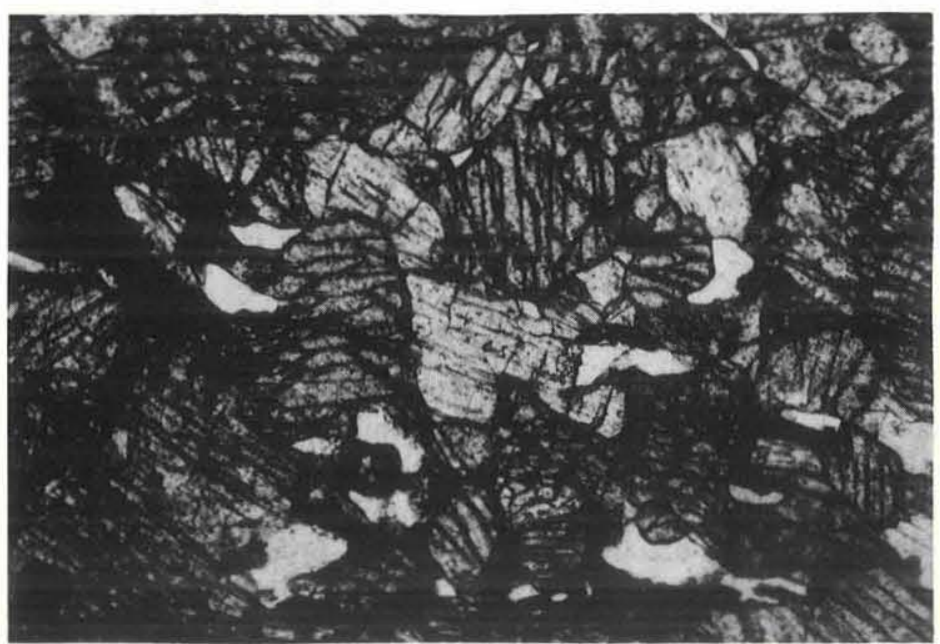

Fotomicrografia 2

Mosaico granoblástico poligonal de wollastonita com um ou outro grão de diopsídio e microclínio intersticial. Observam-se formas ainda regulares e outras estranguladas. Polarizadores descruzados. $\times 48$ 


\section{Fotomicrografia 3}

Wollastonita quebrada e separada por quartzo e diopsídio. Observar a pigmentação, as bordas com reentrâncias preenchidas por quartzo e as terminações arredondadas da wollastonita. Polarizadores semicruzados. $\times 120$

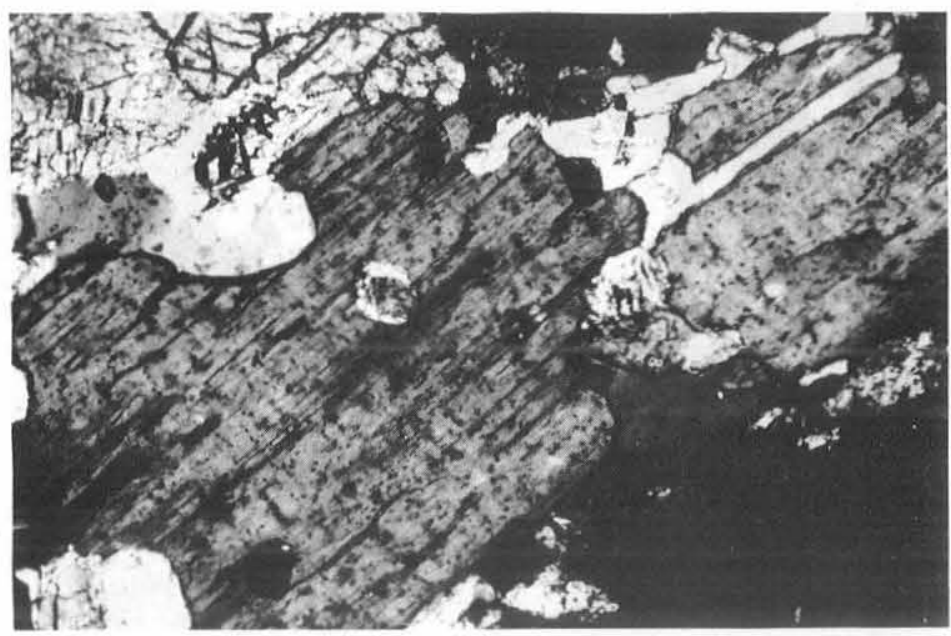

As associações 1 e 2 não contêm quartzo; todas as outras ou fazem parte de quartzitos ou apresentam pelo menos pequena quantidade de quartzo. Calcita e clinozoisita fazem parte de todas as associações e pelo menos na associação 5 a calcita deve ser primária. $\mathrm{O}$ acessório mais comum é a titanita, freqüentemente abundante (até $2 \%$ ), ocorrendo ainda a apatita, zircão (raramente) e opacos.

O quartzo é sempre xenoblástico, com granulação submilimétrica a milimétrica, e compõe mosaicos granoblásticos interlobados ou cordões (textura flaser). Afora raros grãos, nas associações mais cálcicas, apresenta sempre forte extinção ondulante e algumas vezes com bordas microgranuladas. É notável como penetra os outros minerais (principalmente wollastonita, diopsídio e escapolita) formando reentrâncias côncavas (Fotomicrografias 1, 3 e 4).

O clinopiroxênio (diopsídio-salita) é incolor a levemente esverdeado, praticamente não-plecróico com $2 V_{Z}=57^{\circ}, N_{X}=1,685$ e $N_{Z}=1,716$. Apresenta-se com formas mais ou menos equidimensionais ou prismáticas curtas regulares, associado à wollastonita ou em bandas puras (Fotomicrografia 2). Nas rochas quartzosas mostra formas irregulares corroídas ou amebóides, ou constitui pequenas gotas isoladas isorientadas (Fotomicrografia

Fotomicrografia 4

Porfiroblasto de wollastonita, com as típicas reentrâncias e extremidades afinadas. $\mathrm{O}$ material em volta apresenta quartzo, diopsídio, clinozoisita e calcita em arranjo granoblástico interlobado inequigranular. Polarizadores semicruzados. $\times 48$

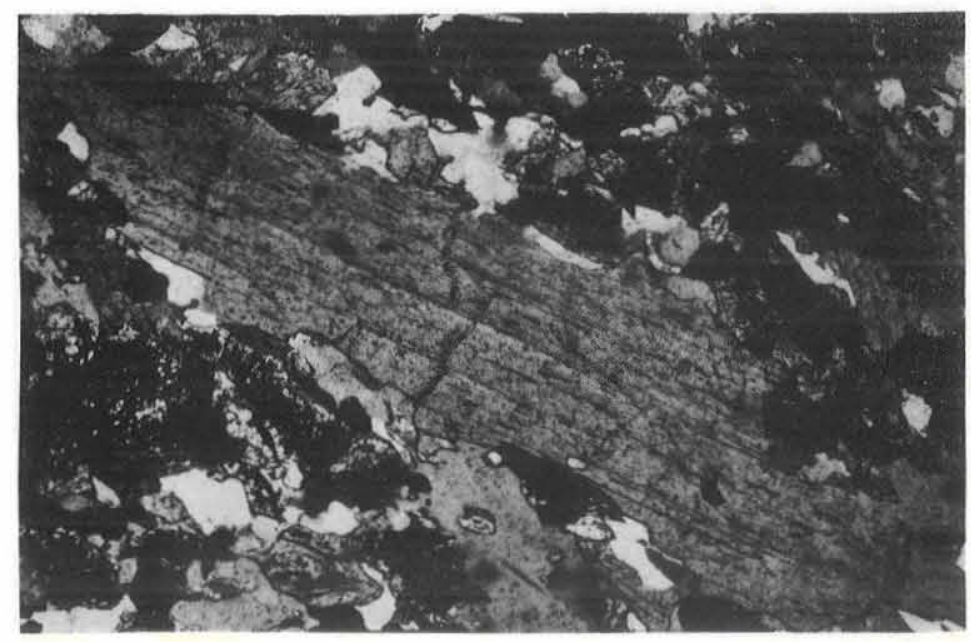




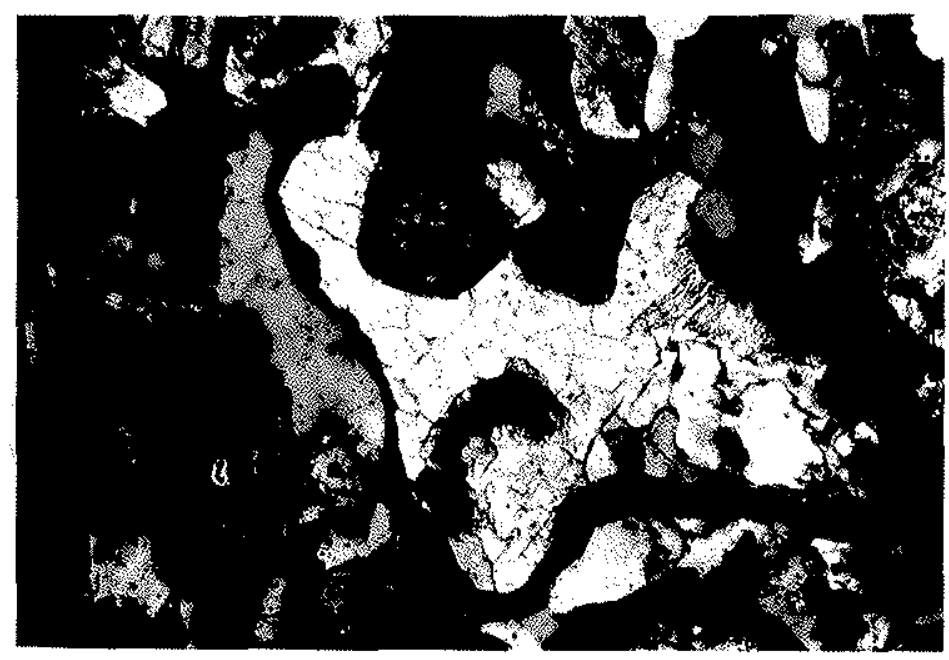

\section{Fotomicrografia 5}

Escapolita, quartzo e diopsídio envolvidos por cordão e massa de granada. Polarizadores cruzados. $\times 150$

1). Ass vezes forma uma mosaico com escapolita, ou aparece sobre esta, e nas porções feldsm páticas tem formas mais regulares, embora sempre arredondadas (Fotomicrografia 6).

A escapolita, incolor, tem hábito semelhante ao do diopsídio ou forma mosaicos de grãos equidimensionais, sobre os quais pode comparecer o diopsídio arredondado. Provavelmente é um termo próximo à meionita (Oliveira e Hypolito, no prelo).

O plagioclásio é representado por andesina e bytownita, que não ocorrem juntas nas mesmas camadas. A andesina aparece associada ao diopsídio e à biotita (Fotomicrografia 6) ou subordinada ao quartzo, tem hábito equidimensional e é sempre geminada segundo a Lei da Albita. A bytownita, de hábito semelhante, mas geminada também segundo a Lei do Periclínio, comparece formando leitos essencialmente feldspáticos, ou restrita a lentes nos quartzitos com wollastonita ou escapolita. Em algumas amostras, ela passa nas bordas para escapolita, sendo o conjunto envolvido por granada.

O microclínio é restrito, ocorrendo nas bandas menos quartzosas, intersticialmente, ou em mosaicos com escapolita e diopsídio. Apresenta-se incipientemente geminado.

A granada forma massas e cordôes que ocupam porções irregulares entre os outros calcossilicatos, ou constitui bolsões mais ou menos lenticulares dentro do quartzito. Nor-

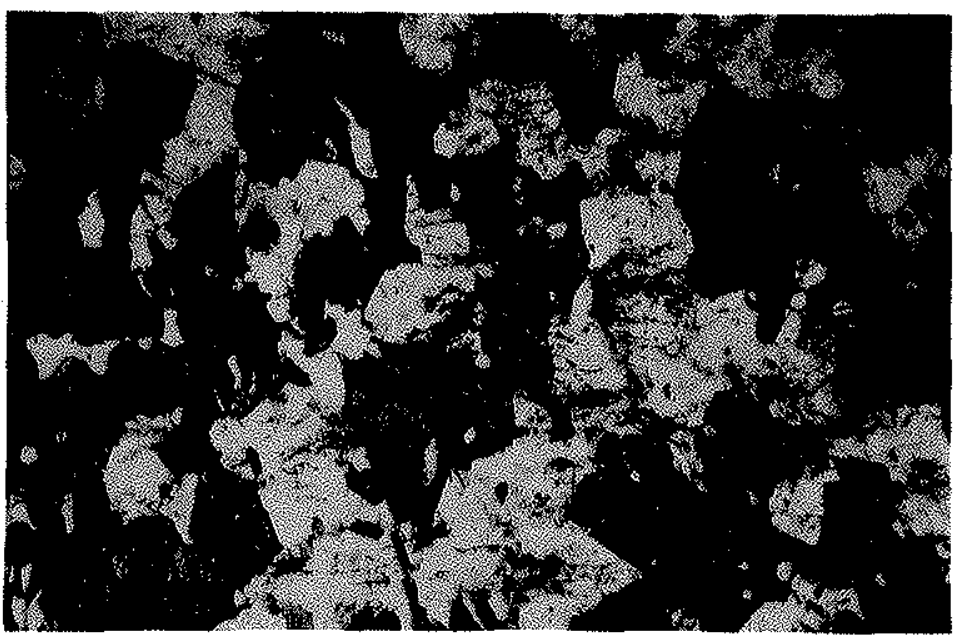

Fotomicrografia 6

Diopsídio, biotita e andesina (pigmentada) em textura granolepidoblástica. Observar os cantos arredondados do diopsídio. Polarizadores descruzados. $\times 30$ 
malmente engloba restos dos outros minerais (inclusive de quartzo), principalmente plagioclásio e escapolita. Não raro se associa à clinozoisita. Também é comum se apresentar em cordões que orlam o plagioclásio ou a escapolita (Fotomicrografia 5).

A biotita, encontrada em uma única amostra, é do tipo avermelhado ( $Z=$ avermelhado e $X=$ amarelo-claro) e apresenta-se em placas submilimétricas isorientadas, associada à andesina e ao diopsídio, estando ausente a titanita (Fotomicrografia 6).

A clinozoisita compõe com calcita massas intersticiais difusas ou provém da alteração do diopsídio. É freqüente se associar aos agrupamentos de grãos da granada, sem no entanto se individualizar.

A calcita ora tem características de mineral primário, ora de secundário. Quando associada à clinozoisita e granada ou, quando aparece nas bordas da wollastonita ou diopsídio, constitui agregados ou grãos irregulares de pequenas dimensões e neste caso, bem como em fraturas, parece ser de alteração. Contudo, sua ocorrência em grãos mais bem formados junto a diopsídio ou em gotas e formas arredondadas isoladas dentro do quartzito poderia ser tida como primária.

Entre os acessórios, o mais comum é a titanita arredondada, que às vezes chega a $2 \%$ da banda, podendo atingir dimensões de até $0,5 \mathrm{~mm}$. A apatita é comum, em quantidades muito pequenas, e o zircão é raro. Os opacos são representados por sulfetos (pirita e calcopirita), provavelmente secundários.

WOLLASTONITA Este mineral comparece em muitas das associações registradas e em algumas das amostras chega a perfazer $90 \%$ em volume. Foram observadas duas formas de ocorrência: na primeira associa-se ao diopsídio, constituindo os dois minerais, praticamente $100 \%$ da amostra, arranjados em textura nematoblástica ou granoblástica poligonal (Moore, 1970) (Fotomicrografia 2); na segunda, prismas ou restos corroídos nas bordas ou formas arredondadas de wollastonita, diopsídio e bytownita, associados à calcita e à clinozoisita, e a massas de granada constituem lentes estreitas e alongadas no quartzito. Entre essas duas formas extremas, encontramos formas intermediárias, sendo interessante notar a presença de porfiroblastos (?) esporádicos de wollastonita (Fotomicrografia 4).

A wollastonita apresenta-se incolor, levemente pigmentada por material opaco granular. Constitui prismas alongados com extremidades mal terminadas e afinadas; é comum apresentarem formas reintrantes, côncavas nas bordas e convexas nas extremidades, principalmente quando o mineral vizinho é o quartzo (Fotomicrografias 3 e 4). Algumas vezes apresentam-se fraturados ou quebrados com as partes separadas por outros minerais (Fotomicrografia 3). Nas texturas poligonais, quando se associa ao diopsídio, esses minerais se apresentam bizelados e com contatos em forma de faixas de birrefringência diferente, sugerindo um acavalamento dos grãos.

Os dados químicos, ópticos e o peso específico (Tabela I), quando comparados aos fornecidos por Deer et al. (1963), revelam tratar-se de wollastonita comum.

CONSIDERAÇOES FINAIS As paragêneses, bem como a situação geológica das rochas wollastoníticas ocorrendo ao lado de granulitos típicos, indicam que elas se formaram sob metamorfismo regional de alto grau ou, mais especificamente, sob as condições da fácies granulito (Turner, 1968).

A descrição petrográfica revela por outro lado a coexistência de associações minerais em desequilíbrio com as mencionadas e que poderiam ser explicadas por fenômenos de retrometamorfismo. Tais associações estariam representadas pelos minerais: granada, escapolita (parte), clinozoisita, microclínio, calcita e, provavelmente, a titanita. 
Tabela I - Propriedades físicas e análise química da wollastonita. Fórmula química na base de seis átomos de oxigênio

\begin{tabular}{|c|c|c|c|c|c|c|}
\hline $\mathrm{SiO}_{2}$ & 51,78 & & & $\mathrm{Si}$ & 5,997 & 600 \\
\hline $\mathrm{Al}_{2} \mathrm{O}_{3}$ & 0,51 & & & $\mathrm{Al}$ & 0,003 & \\
\hline $\mathrm{Fe}_{2} \mathrm{O}_{3}$ & 0,70 & & & $\mathrm{Al}$ & 0,066 & \\
\hline $\mathrm{FeO}$ & 0,26 & & & $\mathrm{Fe}^{+3}$ & 0,054 & \\
\hline $\mathrm{MnO}$ & 0,10 & & & $\mathrm{Fe}^{+2}$ & 0,027 & \\
\hline $\mathrm{MgO}$ & 0,18 & & & & & 5,93 \\
\hline $\mathrm{CaO}$ & 46,30 & & & $\mathrm{Mn}$ & 0,006 & \\
\hline \multirow{7}{*}{ TOTAL } & & & & $\mathrm{Mg}$ & 0,030 & \\
\hline & 99,83 & & & $\mathrm{Ca}$ & 5,748 & \\
\hline & & Peso específico & 2,85 & & & \\
\hline & & $N_{X}$ & 1,619 & & & \\
\hline & & $N_{Y}$ & 1,631 & & & \\
\hline & & $N_{Z}$ & 1,633 & & & \\
\hline & & $2 V_{X}$ & $37^{\circ}$ & & & \\
\hline
\end{tabular}

Existe grande semelhança entre a ocorrência ora estudada e algumas outras já citadas, especialmente as de Nanga Parbat (Misch, 1964) e de Eastern Ghats, India (Mukherjee et al., 1972), as únicas estudadas com certo pormenor.

$\mathrm{Na}$ primeira, Misch considera a zona "wollastonita + bytownita" como a de mais alto grau atingida durante o metamorfismo naquela área. Conclusão semelhante pode se obter para as rochas de Caconde, considerando-se as demais assembléias como indicativas de condições menos intensas.

$\mathrm{O}$ aparecimento da wollastonita poderia ser explicado por duas reações. Para os leitos constituídos essencialmente por wollastonita, esse mineral poderia ter se formado pela reação clássica:

$$
\text { Calcita }+ \text { Quartzo } \rightarrow \text { Wollastonita }+\mathrm{CO}_{2} .
$$

Os valores de $P_{\mathrm{CO}_{2}}$ são discutidos por Misch (1964) com base em dados experimentais e são tidos como bastante inferiores à $P_{\text {total }}$, pois para valores de $P_{\mathrm{CO}_{2}}=2 \mathrm{~Kb}$ a reação acima só se verifica a temperaturas superiores a $700^{\circ} \mathrm{C}$, enquanto que, para $P_{\mathrm{CO}_{2}}=3 \mathrm{~Kb}$, é necessária uma temperatura bem superior a $800^{\circ} \mathrm{C}$, o que não deve ter ocorrido durante o metamorfismo, logo $P_{\mathrm{CO}_{2}}<P_{\text {total }}$.

Já para os leitos em que ocorre associada à bytownita em presença de excesso de sílica, a reação mais aceita seria:

$$
\underset{\text { Grossulária }}{\mathrm{Ca}_{3} \mathrm{Al}_{2} \mathrm{Si}_{3} \mathrm{O}_{12}}+\underset{\text { Quartzo }}{\mathrm{SiO}_{2}} \rightarrow \underset{\text { Wollastonita }}{2} \mathrm{CaSiO}_{3}+\mathrm{CaAl}_{2} \mathrm{Si}_{2} \mathrm{O}_{8}
$$

Segundo Newton (1966), esta última reação projetada num diagrama PT, juntamente com o ponto tríplice andalusita-cianita-sillimanita, mostra que dentro do campo de estabilidade da sillimanita ela só se verifica a uma temperatura mínima de $680^{\circ} \mathrm{C}$ e pressões mínimas de $4 \mathrm{~Kb}$.

Como foi mencionado no inicio deste trabalho, as associaçôes pelíticas mais próximas contêm o mineral sillimanita. Além disso, Oliveira (1973) descreve na área vizinha a ocorrência de kinzigitos portadores de cordierita, granada e sillimanita. Com base em para- 
gênese semelhante, Hutcheon et al. (1974) estabeleceram um termômetro e um barômetro geológicos obtendo para os kinzigitos do "Daly Bay Complex", Canadá, temperaturas que variam entre 610 e $760^{\circ} \mathrm{C}$ e pressões entre 5,3 e $6,6 \mathrm{~Kb}$.

Devido à semelhança petrográfica e petrológica dos kinzigitos de São José do Rio Pardo com os estudados por Hutcheon et al. (1974), pode-se admitir perfeitamente que os primeiros devem também ter se formado dentro do mesmo intervalo de PT, ou seja, 610$-760{ }^{\circ} \mathrm{C}$ e 5,3 a $6,6 \mathrm{~Kb}$. Estes valores são perfeitamente compatíveis com os obtidos durante a análise da formação de wollastonita (ver acima).

Pode-se assim concluir com certa segurança que as rochas granulíticas da região de Caconde, especialmente as calcossilicáticas portadoras de wollastonita, se formaram num intervalo de temperatura entre 680 e $760^{\circ} \mathrm{C}$ e com pressões superiores a $4 \mathrm{~Kb}$, provavelmente entre 5,3 e 6,6 Kb.

Desta forma, com base nos parâmetros fornecidos por Turner (1968) para a fácies granulito - pressões entre 3 e $9 \mathrm{~Kb}$ e temperaturas entre 700 e $800{ }^{\circ} \mathrm{C}-$, poderíamos classificar a área como de média pressão, considerando os valores numéricos obtidos. Esta conclusão está de acordo com a classificação fornecida por Winkler (1974), que considera como médias as pressões entre 3 e 5,5 $\mathrm{Kb}$ (Tab. 15.3 da obra citada).

Contudo, as classificações das séries de fácies metamórficas apresentadas pelos principais autores não são concordantes na fixação de limites, separando os campos de baixa, média e alta pressão. Para Miyashiro (1973), por exemplo, temperaturas de $700^{\circ} \mathrm{C}$ e pressões de $7 \mathrm{~Kb}$ são consideradas ainda dentro da série de baixa pressão (Fig. 3.3 da obra citada). Turner (1968) considera os valores para fácies de baixa pressão um pouco inferiores aos de Miyashiro, embora sem precisar quanto. $\mathrm{O}$ que se observa na análise desses trabalhos é que as áreas metamórficas têm sido classificadas ou com base nas paragêneses minerais encontradas ou na presença de algum mineral índice. Assim, para Miyashiro (1973), o mineral cordierita é característico de áreas de baixa pressão, não sendo estável em áreas de pressão média. Katz (1972) utiliza o mesmo critério para classificar parte das rochas metamórficas do Pré-Cambriano do Ceilão como de baixa pressão.

Em resumo, conclui-se que a área estudada pode ser classificada tanto de média como de baixa pressão em função do critério ou do autor adotado e que os dados disponíveis ainda são insuficientes para uma conclusão definitiva.

Assim, a interpretação dada por Leonardos (1974) e Leonardos e Fyfe (1974), considerando a área como enquadrada em um cinturão metamórfico de "baixa" pressão é válida segundo os critérios de Miyashiro (1973), sendo discutível se considerarmos valores aceitos por outros autores (Turner, 1968, e Winkler, 1974).

\section{BIBLIOGRAFIA}

BARD, J. P. - 1969 - Le metamorphisme regional progressif des Sierras d'Aracena en Andalousie Occidentale (Espagne). University of Montpellier

DEER, W. A., HOWIE, R. A. e ZUSSMAN, J. - 1963 - Rock forming minerals, vol. 2, Chain silicates. Longmans Green Co. Ltd., Londres

GOMES, C. B., COUTINHO, J. M. V. e OLIVEIRA, A. B. de - 1966 - "Pargasita em dolomitos metamórficos do município de Tapiratiba, SP". An. Acad. Brasil. Cienc. 38: 39-46

HAPUARACHCHI, D. J. A. C. - 1968 - "Cordierite and wollastonite bearing rocks of southwest Ceylon". Geol. Mag. 105: 317-324

HUTCHEON, I., FROESE, E. e GORDON, T. M. - 1974 - "The assemblage quartz-sillimanite-garnet-cordierite as an indicator of metamorphic conditions in the Daly Bay Complex". N.W.T. Contr. Mineral. Petrol. 44: 29-34 
KATADA, M. - 1965 - "Petrography of Ryoke metamorphic rocks in nothern Kiso district, central Japan". J. Jap. Assoc. Mineral. Petrol. Econ. Geol. 53: 77-90, 155-164 e 187-204

KATZ, M. B. - 1972 - "Facies series of the High-Grade metamorphic rocks of the Ceylon precambrian". XXIV Int. Geol. Congress. Section 2, Petrology, 43-51

LEONARDOS JR., O. H. - 1974 - "Origin and provenance of fossil and recent monazite deposits in Brazil". Econ. Geology, 69: 1126-1128

LEONARDOS JR., O. H. e FYFE, W.S. - 1974 - "Ultrametamorphism and melting of a continental margin: the Rio de Janeiro region, Brazil". Contr. Mineral. Petrol. 46: 201-214.

MISCH, P.H. - 1964 - "Stable association wollastonite anortite, and other calc-silicate assem" blages in amphibolite-facies crystalline schists of Nanga Parbat, northwest Himalayas". Beitr. MineraI. Petrogr. 10: 315-356

MIYASHIRO, A. - 1953 - "Progressive metamorphism of the calcium-rich rocks of the Gosaisyo-Takanuki district, Abukuma Plateau, Japan". Jap. J. Geol. Geogra. 23: 81-107

MIYASHIRO, A. - 1958 - "Regional metamorphism of the Gosaisyo-Takanuki district in the central Abukuma Plateau". Tokyo Univ. Fac. Sci. J., 2(11): 219-272

MIYASHIRO, A. - 1973 - Metamorphism and metamorphic belts. George Allen e Unwin Ltd., Londres

MOORE, A. C. - 1970 - "Descriptive terminology for the textures of rocks in granulite facies terrains". Lithos. 3: 123-128

MUKHERJEE, A. e REJE, S. M. - 1972 - "Stability of wollastonite in the granulite facies: some evidences from the Eastern Ghats, India". N. Jb. Miner. Abh. 118: 23-42

NEWTON, R. C. - 1966 - "Some calc-silicate equilibrium relations". Am. J. Sci. 264: 204-222

OLIVEIRA, M. A. F. de - 1973 - "Petrologia das rochas metamórficas da região de São José do Rio Pardo, SP". Rev. Bras. Geociências 3: 257-278

OLIVEIRA, M. A.F. de e HYPOLITO, R. (no prelo) - "Rochas calcossilicáticas da região de São José do Rio Pardo, SP". Anais do XXVII Congresso Brasileiro de Geologia

OLIVEIRA, M. A.F. de e ALVES, F. R. (no prelo) - "Geologia e petrografia da região de Caconde, SP". Anais do XXVIII Congresso Brasileiro de Geologia

TURNER, F. J. - 1968 - Metamorphic petrology: mineralogical and field aspects. McGraw-Hill Book Co., New York

WILLIAMS, H., TURNER, F.J. e GILBERT, C. M. - 1970 - Petrografia. Editora Polígono e Editora da Universidade de São Paulo

WINKLER, H. G. F. - 1974 - Petrogenesis of metamorphic rocks. 3. ed., Springer Verlag-Berlim 